\title{
Studies on Sulfatides by Quadrupole Ion-Trap Mass Spectrometry with Electrospray Ionization: Structural Characterization and the Fragmentation Processes that Include an Unusual Internal Galactose Residue Loss and the Classical Charge-Remote Fragmentation
}

\author{
Fong-Fu Hsu and John Turk \\ Department of Internal Medicine, Mass Spectrometry Resource, Division of Endocrinology, Diabetes, and \\ Metabolism, Washington University School of Medicine, St. Louis, Missouri, USA
}

\begin{abstract}
The structural characterization of sulfatides by collisional-activated dissociation (CAD) quadrupole ion-trap tandem mass spectrometric methods with electrospray ionization is described. When subjected to CAD in the negative-ion mode, the $[\mathrm{M}-\mathrm{H}]^{-}$ions of sulfatides yield abundant structurally informative ions that permit unequivocal assignments of the long-chain base, and fatty acid constituent including the location of double bond. The identification of the position of the double bond on the fatty acyl substituent is based on the observation of the series of the ions arising from classical charge-remote fragmentation processes similar to those observed by high-energy CAD and by tandem quadrupole mass spectrometry. An unusual internal galactose residue loss due to a rearrangement process was also observed. The $[\mathrm{M}-\mathrm{H}]^{-}$ions of sulfatides also dissociates to a ceramide anion, which undergoes consecutive fragmentation processes to yield ions informative for identification of the ceramide moiety and permits distinction the sulfatide with a sphingosine subclass from that with a sphinganine long-chain base subclass. The $\mathrm{MS}^{2}$-spectra of the sulfatide subclass with a sphingosine LCB and a $\alpha$-hydroxy fatty acyl substituent (d18:1/hFA-sulfatide) are featured by the prominent ion sets of $m / z 568,550,540$, and 522, originated from a primary cleavage of the fatty acyl $\mathrm{CO}-\mathrm{CH}(\mathrm{OH})$ bond, and are readily differentiable from those arising from the non-hydroxy sulfatide subclass (d18:1/nFA-sulfatide), in which the ion sets are of low abundance. The fragmentation pathways of sulfatides under low-energy CAD are proposed. The pathways are supported by the $\mathrm{MS}^{2}$ - and $\mathrm{MS}^{3}$-spectra of various compounds, and of their H-D exchanged analogs. (J Am Soc Mass Spectrom 2004, 15, 536-546) (c) 2004 American Society for Mass Spectrometry
\end{abstract}

$\mathrm{T}$ he sphingolipid sulfatide (3-sulfogalactosylceramide) (I) is a ceramide galactoside 3 -sulfate which contains a 3-sulfogalactosyl moiety in a glycoside linkage to a ceramide in which a long-chain fatty acid residue is linked to the amino group of a long chain base (LCB), mainly a sphingosine. Sulfatide is widely distributed in animal tissue, particularly in cell membranes, and is involved in some diseases [1-3]. It is an important biological substance and executes many biological functions [4-7]. The biological role of sulfatide is beyond the scope of this study. Several reviews and articles are referred to readers for detail [1-10].

Published online February 2, 2004

Address reprint requests to Dr. F.-F. Hsu, Box 8127, Washington University School of Medicine, 600 S. Euclid Street, St. Louis, MO 63110, USA. E-mail: fhsu@im.wustl.edu
Tandem mass spectrometry with soft ionization methods towards to the structural elucidation of sulfatides has been demonstrated. A detailed study was reported by Nagai and Ohashi [11], who investigated the fragmentation pathways of sulfatides in both positive-ion and negative-ion modes by use of FAB in combination with tandem sector and with triple quadrupole mass spectrometry. Low-energy CAD tandem quadrupole mass spectrometry with electrospray ionization was recently used for determination of the fragmentation patterns and characterization of the sulfatide molecular species expressed in different cells $[12,13]$.

FAB sensitivities for sulfatides in both positive- and negative-ion modes are poor, with the latter a few times more sensitive than the former. Even in the negative-ion mode, low nmol sample quantities were required to obtain a decent spectrum [11]. ESI offers superb sensi- 
tivity for sulfatides in negative-ion mode, and subpicomole sample quantities provides spectra of excellent quality. This may be attributed to the fact that the anionic sulfate of the molecule is readily ionizable. In contrast, the sensitivity of sulfatides by ESI in positiveion mode is poor, and only a $10^{-3}$-order magnitude of sensitivity to that observed in the negative-ion mode can be obtained. Herein, we reported the studies conducted in negative-ion mode with ESI, using mainly a quadrupole ion-trap instrument along with a triple quadrupole mass spectrometer.

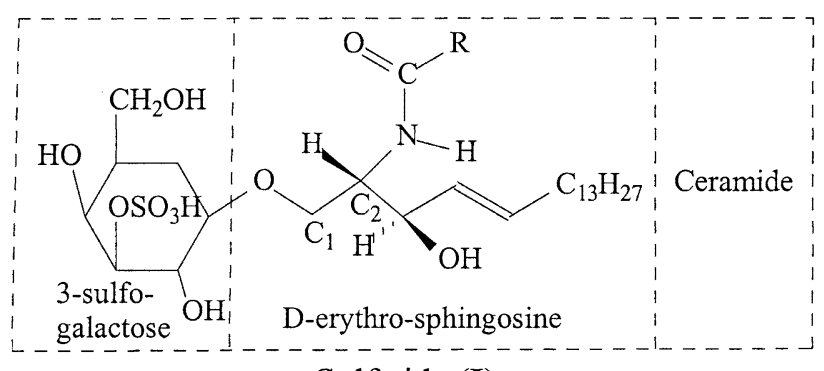

Sulfatide (I)

\section{Experimental}

\section{Sulfatide Standards and Abbreviations}

Sulfatides from bovine brain were purchased from Sigma Chemical (St. Louis, MO). H-D exchange was achieved by dissolving samples in $\mathrm{CH}_{3} \mathrm{OD}$. The solvent was evaporated under a stream of nitrogen, and the residue was reconstituted in $\mathrm{CH}_{3} \mathrm{OD}$ before analysis. The exchange gives a greater than $95 \%$ conversion of exchangeable hydrogen to deuterium.

The designation of sulfatide is in the form of dLCB/ FA, with d denoting a dihydroxy long chain base (LCB) and FA refers to fatty acid. The sphingosine (sphingenine) and sphinganine LCBs, for examples, were designated as d18:1 and d18:0, respectively. Fatty acyl moieties with or without $\alpha$-hydroxyl substituents were denoted as hFA or nFA, respectively.

\section{Mass Spectrometry}

ESI tandem mass spectrometric analyses with an iontrap instrument were performed on a Finnigan (San Jose, CA) LCQ DECA equipped with an electrospray ion source and operated by XCalibur software. Solution of sulfatides was prepared in methanol at final concentration of $10 \mathrm{pmol} / \mu \mathrm{L}$. The sulfatide solution yields intense deprotonated molecular anions $\left([\mathrm{M}-\mathrm{H}]^{-}\right)$in negative-ion mode. Samples were infused $(1 \mu \mathrm{L} / \mathrm{min})$ into the ESI source employing nitrogen as nebulizing gas. The syringe and the fused-silica capillary transfer line were washed thoroughly with acetonitrile before the H/D-exchanged samples were infused. The heated capillary temperature was $250{ }^{\circ} \mathrm{C}$, and the electrospray needle was set at $4.5 \mathrm{kV}$ with the skimmer at ground potential. The automatic gain control of the ion trap was set to $5 \times 10^{7}$, with a maximum injection time of $400 \mathrm{~ms}$. Helium was used as the buffer and collision gas at a pressure of $1 \times 10^{-3}$ mbar. MS $^{n}$ experiments were carried out with a relative collision energy ranging from 55 to $60 \%$ and with an activation $\mathrm{q}_{\mathrm{z}}$ value ranging from 0.2 to 0.45 . The activation time was set at $100 \mathrm{~ms}$ and the mass selection window for the precursor ions were set at $1.6 \mathrm{Da}$. The mass resolution was $0.6 \mathrm{Da}$ at half peak height. Product-ion spectra obtained with a triple stage quadrupole instrument (TSQ) were performed on a Finnigan TSQ-7000 mass spectrometer and controlled by Finnigan ICIS software operated on a DEC alpha station. The precursor ions selected in the first quadrupole (Q1) were collided with Ar (2.3 mTorr) in the rf-only second quadrupole (Q2) using a collision energy of $60-65 \mathrm{eV}$, and were mass analyzed in the third quadrupole (Q3). Both Q1 and Q3 were operated at unit mass resolution. Thus, components that varied in the degree of unsaturation, and varied by the presence of hydroxyl functional group or other modifications resulting in mass shifts of only a few daltons in mixtures can be separated. The mass spectra were accumulated in the profile mode, typically for $10-30 \mathrm{~min}$ for a tandem mass spectrum.

\section{Results and Discussion}

Common Fragmentation Processes Occurred to Sulfatides Observed by Tandem Quadrupole and Ion-Trap Mass Spectrometry

As illustrated in Figure 1a, the product-ion spectrum of the $[\mathrm{M}-\mathrm{H}]^{-}$ion of $\mathrm{d} 18: 1 / 24: 1$-sulfatide at $\mathrm{m} / \mathrm{z} 888$ obtained with a TSQ instrument is dominated by $m / z$ 97, representing a $\mathrm{HOSO}_{3}^{-}$ion [11-13], and ions at $m / z 259$, 257 , and 241 that reflect the 3-sulfogalactosyl moiety are also present. In contrast, ions with masses smaller than $200 \mathrm{Da}$ were not observed in the $\mathrm{MS}^{2}$-spectrum of $\mathrm{m} / \mathrm{z}$ 888 obtained with a ITMS (Figure 1b), because of the low-mass cutoff [14]. However, the fragment ions are more evenly distributed in the recorded mass range. The $m / z 259$ and $m / z 257$ ions may arise from the same fragmentation processes as that leading to the formation of the $m / z 390$ ion, by cleavage of the C2-C3 bond of the LCB. The anionic charge of the former two ions most likely resides on the sulfate, whereas the charge site of the $m / z 390$ ion probably is on the amide nitrigen. The fragmentation pathways account for the formation of the $m / z 390$ ion may arise from the elimination of the LCB as an aldehyde $\left(\mathrm{CH}_{3}\left(\mathrm{CH}_{2}\right)_{7} \mathrm{CH}=\mathrm{CHCHO}\right)$ (Scheme $\mathbf{1 A}$, Route a) or from expulsion of $\left(\mathrm{CH}_{3}\left(\mathrm{CH}_{2}\right)_{7} \mathrm{CH}=\mathrm{CHCHO}+\right.$ $\mathrm{H}_{2}$ ) (Scheme 1A, Route b). These fragmentation processes are consistent with the observation of the ions at $\mathrm{m} / \mathrm{z}$ 259, representing a galactose 3-sulfate ion (c1) (Scheme 1B, Route a) and at $m / z$ 257, probably representing a galactono-1,5-lactone 3-sulfate anion (c2) (Scheme 1B, Route b). Further loss of $\mathrm{H}_{2} \mathrm{O}$ from $m / z 259$ gives rise to $m / z$ 241, probably representing several isomers of anhydro galactosylpyranose 3-sulfate (c3) 

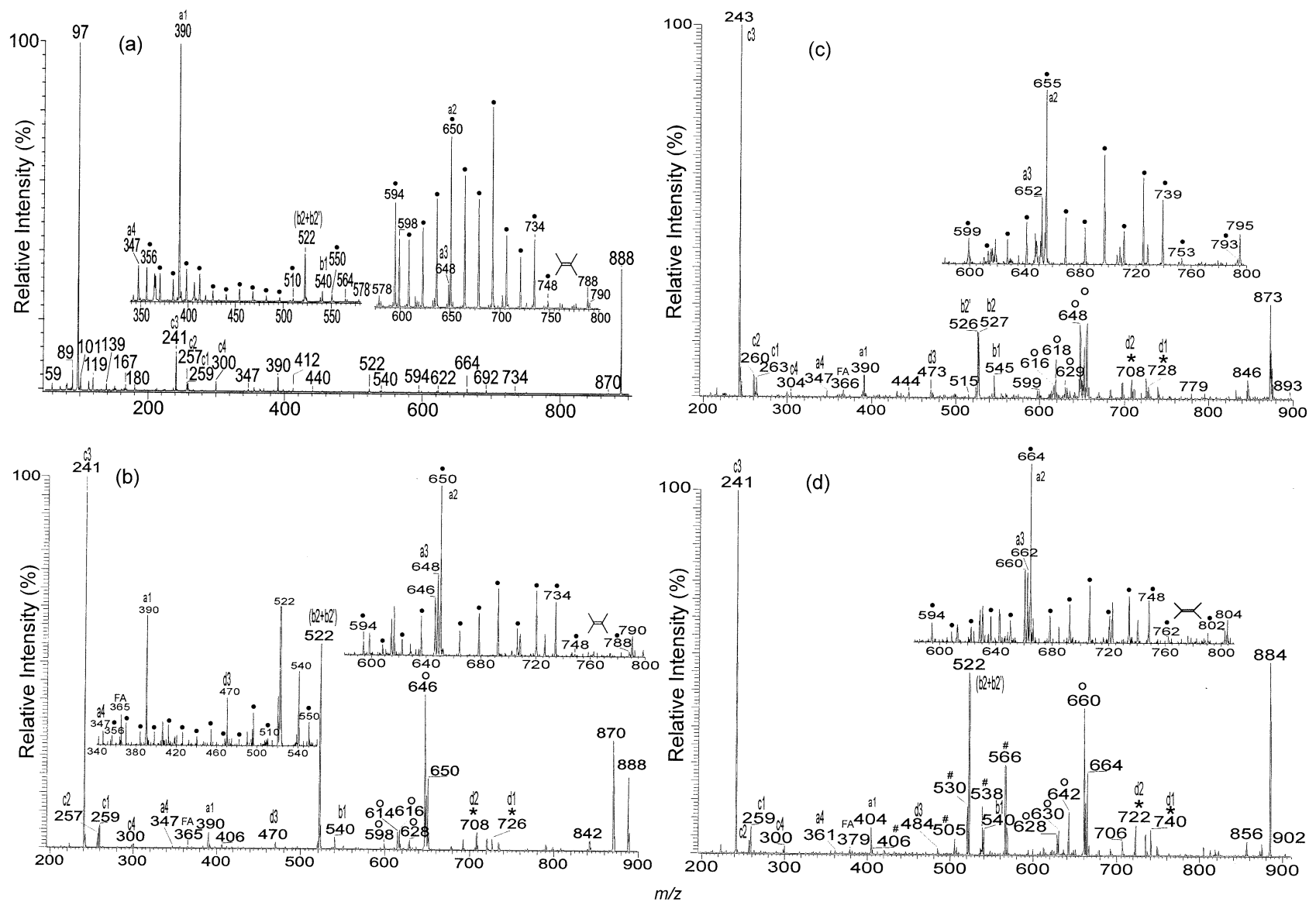

Figure 1. The $\mathrm{MS}^{2}$-spectra of the $[\mathrm{M}-\mathrm{H}]^{-}$ions of (a) d18:1/24:1(15)-sulfatide at $\mathrm{m} / \mathrm{z} 888$ obtained with TSQ at $65 \mathrm{eV}$, of (b) d18:1/24:1(15)-sulfatide at $\mathrm{m} / \mathrm{z} 888$, (c) $d_{5}$-d18:1/24:1(15)-sulfatide at $\mathrm{m} / \mathrm{z} 893$, and of (d) d18:1/25:1(16)-sulfatide at $m / z$ 902, obtained with ITMS at 60\% relative collision energy (q $=0.25$ ). The insets in Panels c-d were acquired under the same condition with $\mathrm{q}=0.45$. The ion series (inset, marked with a center dot) from CRF clearly locates the position of double bond of the fatty acyl moiety of the molecules. Please also note that the $\mathrm{m} / \mathrm{z} 902$ ion (Panel d) also consists of a d18:2/h24:1-sulfatide isomer, which gives ions at $m / z$ 566, 538, 530 and 505 (marked with a number sign); ions arising from the internal galactose residue losses are marked with an asterisk; ions reflecting the ceramide moiety are marked with a degree symbol.

anion. Alternately, the $m / z 241$ ion can arise from loss of a ceramide (Scheme 1C, Route a). This fragmentation process also gives rise to $\mathrm{m} / \mathrm{z} 646$ (Scheme 1C, Route b), corresponding to a deprotonated d18:1/24:1-ceramide anion. The assignments of the ion configurations are consistent with the observation of the mass shifts of the analogous ions in the $\mathrm{MS}^{2}$-spectrum of $d_{5}$-d18:1/24:1sulfatide at $\mathrm{m} / \mathrm{z} 893$ (Figure 1c) and are further supported by the MS $^{3}$-spectra of $\mathrm{m} / \mathrm{z} 259(888 \rightarrow 259)$ (Figure 2a) and $m / z 241(888 \rightarrow 241)$ (data not shown).

In addition to the above ions reflecting the sugar moiety of the molecule, the spectra (Figure 1a and b) also contain the $m / z 650$ ion (a2) $(888-238)$, arising from loss of the d18:1-LCB as a $\alpha, \beta$-unsaturated aldehyde [HCOCH-CH $\left(\mathrm{CH}_{2}\right)_{12} \mathrm{CH}_{3}, 238 \mathrm{Da}$ ] (Scheme 2A, Route a), and the $\mathrm{m} / \mathrm{z} 648$ ion (a3), arising from the losses of the aldehyde and $\mathrm{H}_{2}$, simultaneously [888 - $(238+2)$ ] (Route b). The direct loss of the fatty acyl as a ketene from $[\mathrm{M}-\mathrm{H}]^{-}$via the $\mathrm{NH}-\mathrm{CO}$ bond cleavage results in $\mathrm{m} / \mathrm{z} 540$ (b1), which undergoes a water loss to yield the $m / z 522$ ion $\left(\mathrm{b} 2+\mathrm{b} 2^{\prime}\right)$, probably via two separate pathways as shown in Scheme 2B. This speculation is based on the findings from the product-ion spectrum of the $\mathrm{H}$-D exchanged $d_{5}$-d18:1/24:1-sulfatide at $\mathrm{m} / \mathrm{z} 893$ (Figure 1c), which contains the analogous ions at $\mathrm{m} / \mathrm{z}$ 527 and 526 , by losses of $\mathrm{HDO}$ and $\mathrm{D}_{2} \mathrm{O}$, respectively. The $\mathrm{m} / \mathrm{z} 540$ ion also forms a 1-O-2'-aminoethenyl galactosyl 3-sulfate ion $(\mathrm{m} / \mathrm{z} 300$, c4), via the simultaneous losses of the LCB as an aldehyde and $\mathrm{H}_{2}$ as above described (Scheme 2B, Route c). The fragmentation process is supported by the $\mathrm{MS}^{3}$-spectrum of $\mathrm{m} / \mathrm{z} 540$ $(888 \rightarrow 540)$ (Figure $2 b$ ). The anionic charge site of the above ions mostly likely resides at the sulfate at C-3 of the galactosylpyranoside. Alternately, the charge site could also reside on the nitrogen or oxygen of the amide. This assumption is based on the observation of the $m / z 646$ ion $(888$ - 242), probably arises from expulsion of an anhydro galactosylpyranose 3-sulfate (242 Da) to an ion equivalent to a deprotonated d18:1/ 24:1-ceramide (Scheme 1C, Route b). The $\mathrm{m} / \mathrm{z} 646$ ion 
A

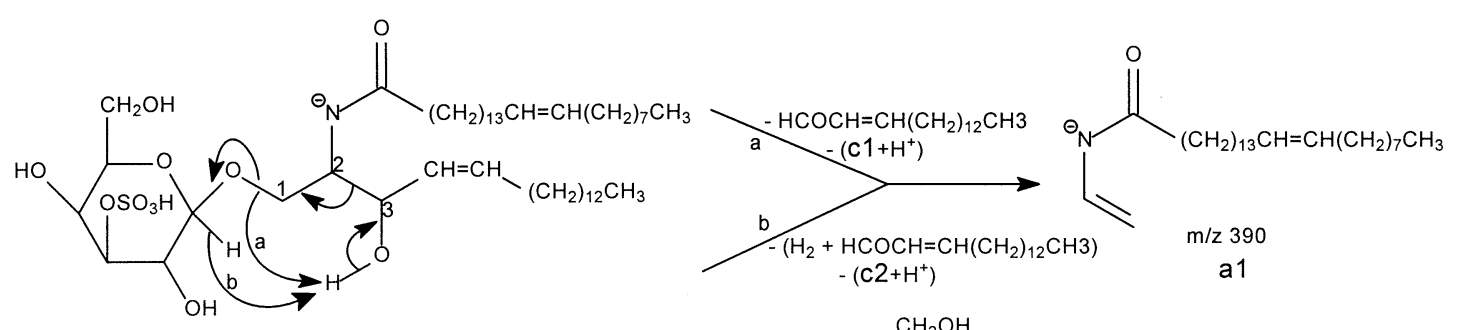

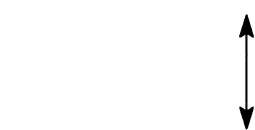

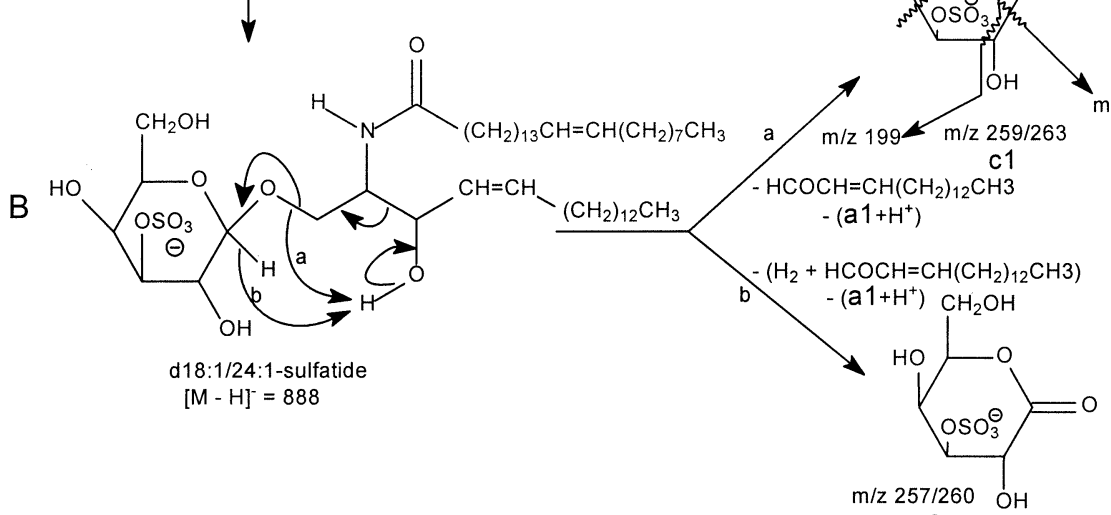

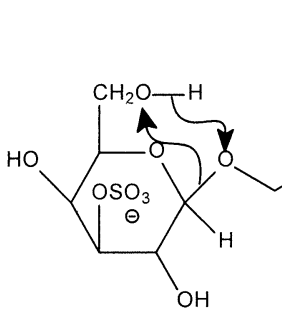

c2

C

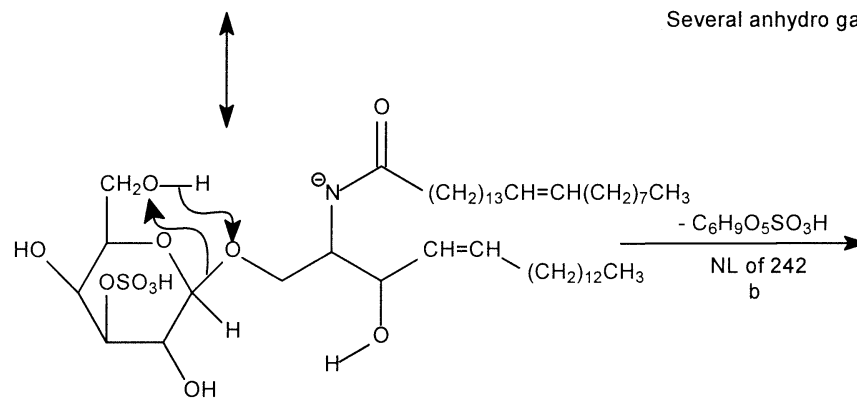

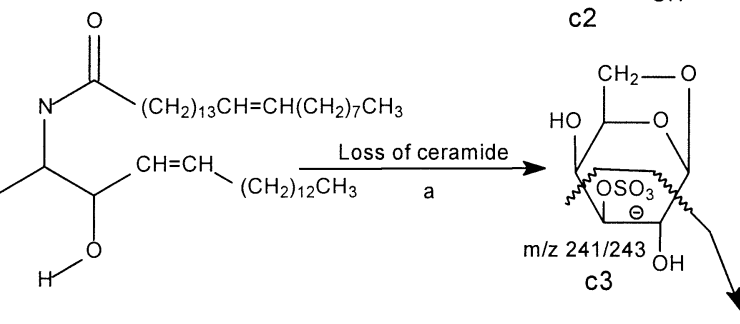

$\mathrm{m} / \mathrm{z} 139 / 140$

$\mathrm{m} / \mathrm{z} 139$

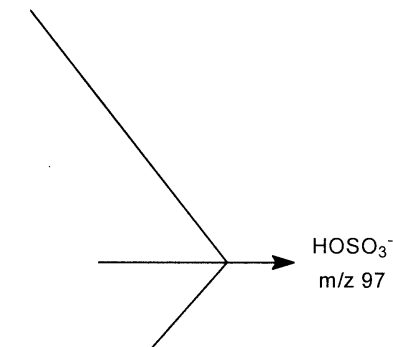

Undergo ceramide-like fragmentation pathways

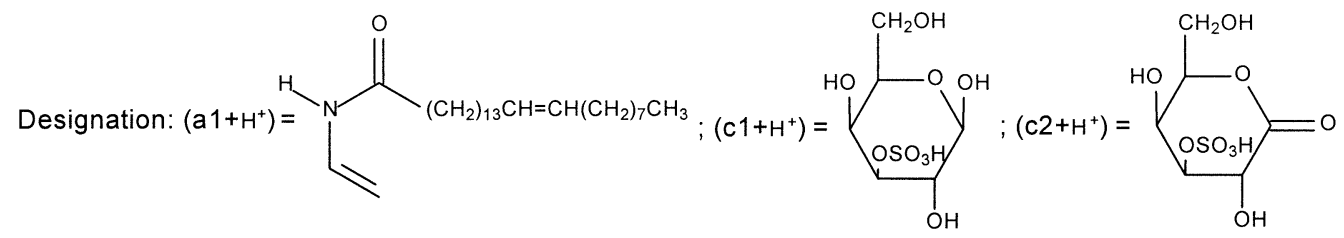

Scheme 1. The common fragmentation pathways proposed for the $[\mathrm{M}-\mathrm{H}]^{-}$ions of sulfatides, as exemplified by d18:1/24:1-sulfatide at $m / z 888$.

yields the ions at $\mathrm{m} / \mathrm{z} 628\left(646-\mathrm{H}_{2} \mathrm{O}\right), 616(646-$ $\mathrm{HCHO}), 614$ [(646 - $\left.\left(\mathrm{H}_{2}+\mathrm{HCHO}\right)\right]$, and 598 [646 $\left.\left(\mathrm{H}_{2} \mathrm{O}+\mathrm{HCHO}\right)\right]$, via the consecutive dissociation processes to expel a $\mathrm{H}_{2} \mathrm{O}, \mathrm{HCHO},\left(\mathrm{H}_{2}+\mathrm{HCHO}\right)$, and $\left(\mathrm{H}_{2} \mathrm{O}\right.$
$+\mathrm{HCHO}$ ) respectively. These fragmentation processes are supported by the $\mathrm{MS}^{3}$-spectrum of $\mathrm{m} / \mathrm{z} 646(888 \rightarrow$ 646) (Figure 2c) which contains ions including $\mathrm{m} / \mathrm{z} 408$ $\left[646-238\left(\mathrm{HCOCH}=\mathrm{CH}\left(\mathrm{CH}_{2}\right)_{12} \mathrm{CH}_{3}\right)\right], 406[646-240$ 
(a) Full ms $388.8 @ 50.00259 .0 @ 28.00$

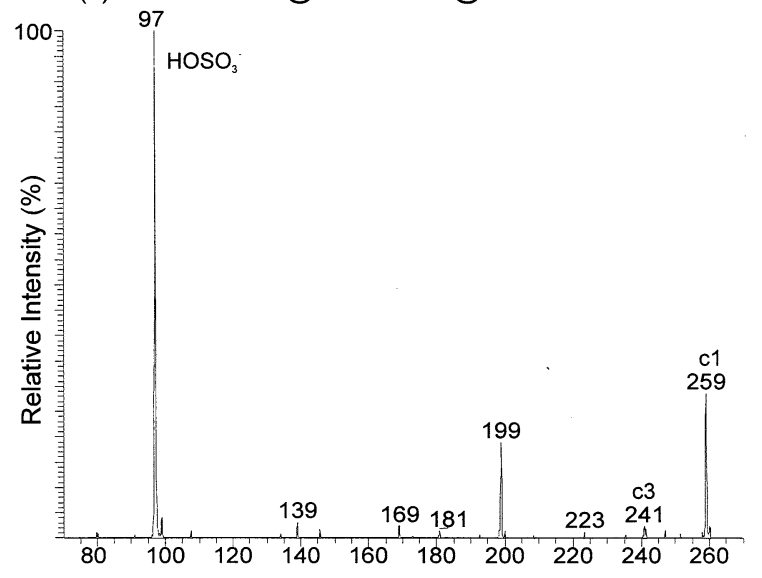

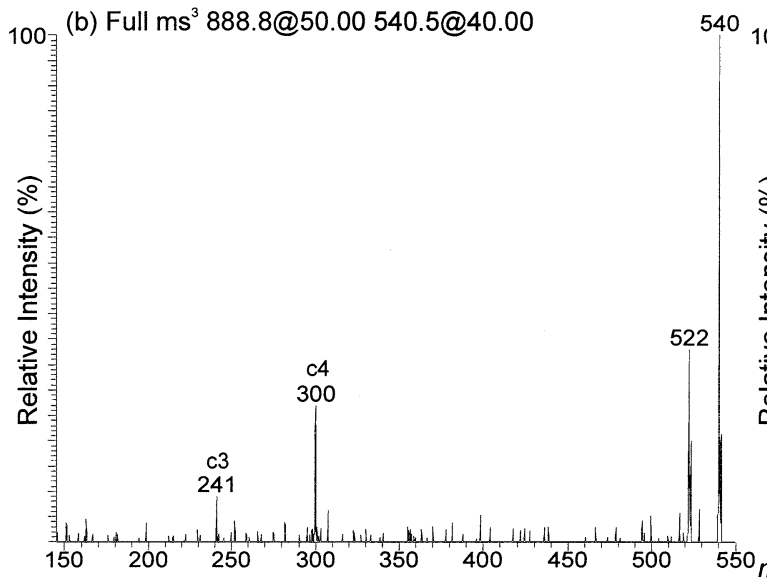

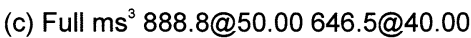

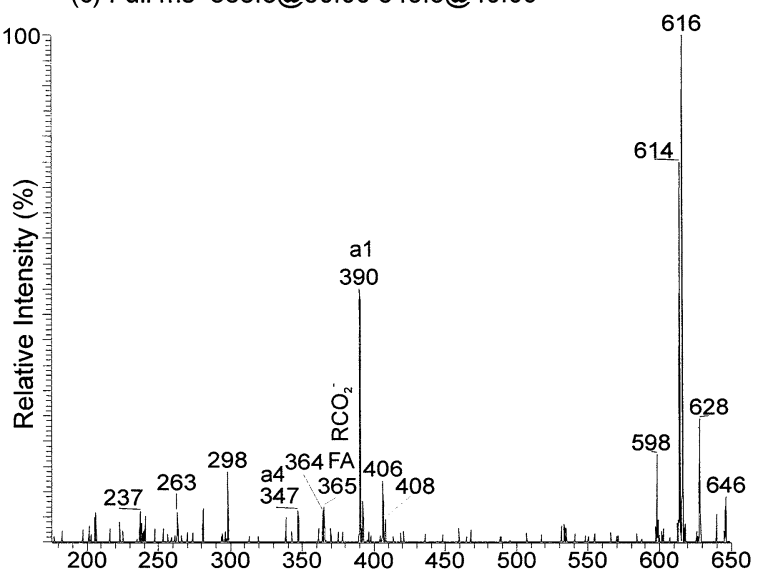

(d) Full ms $3888.8 @ 50.00650 .5 @ 45.00$

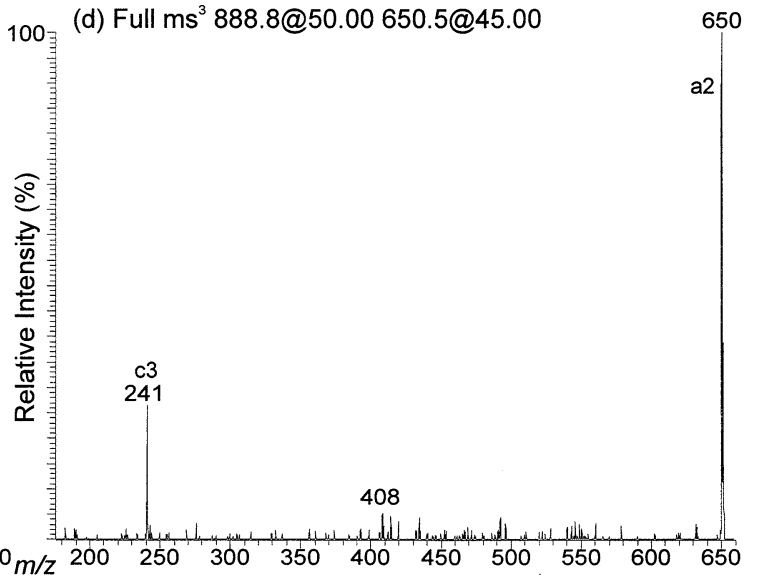

Figure 2. The $\mathrm{MS}^{3}$-spectra of (a) $m / z 259$ (888 $\rightarrow$ 259), (b) $m / z 540(888 \rightarrow 540),(\mathbf{c}) m / z 646(888 \rightarrow 646)$, and (d) $(888 \rightarrow 650)$

$\left.\left(238+\mathrm{H}_{2}\right)\right], 390(\mathrm{a} 1)\left(408-\mathrm{H}_{2} \mathrm{O}\right), 365\left(\mathrm{C}_{23} \mathrm{H}_{45} \mathrm{CO}_{2}^{-}\right), 364$, 298 , and 263, similar to those observed for d18:1/24:1ceramide [19]. A similar fragmentation pathway to yield a deprotonated $\mathrm{d} 18: 1 / 25: 1$-ceramide at $\mathrm{m} / \mathrm{z} 660$, along with ions at $m / z 642,630$, and 628 is also observed in the $\mathrm{MS}^{2}$-spectrum of d18:1/25:1-sulfatide at $\mathrm{m} / \mathrm{z} 902$ (Figure 1d).

The $m / z 347$ ion (a4) may derive from homolytic cleavage of the $\mathrm{NH}-\mathrm{CO}$ bond, in which the anionic charge resides on the oxygen (Scheme $2 \mathrm{C}$ ). An analogous ion at $m / z 361$ was observed for the d18:1/25:1sulfatide (Figure 1d). The above proposed fragmentation pathways are also supported by the $\mathrm{MS}^{3}$-spectra of $m / z 650(888 \rightarrow 650)$ (Figure $2 d)$, and $m / z 648(888 \rightarrow 598)$ (data not shown). The two spectra are dominated by $m / z$ 241, an anhydro galactosylpyranose 3-sulfate anion.

\section{The "Classical Charge-Remote Fragmentation} Processes" Observed by Low-Energy CAD Tandem Mass Spectrometry

One of the most interesting findings in the $\mathrm{MS}^{2}$-spectra of sulfatides under low energy CAD obtained with a TSQ (Figure 1a, inset) [13] and ITMS (Figure 1b, inset) is that ions resembling those reported at high energy $(\mathrm{keV})$ via charge-remote fragmentation (CRF) [15-17] are also present. One series of ions [ ${ }^{-} \mathrm{YCO}\left(\mathrm{CH}_{2}\right)_{\mathrm{x}} \mathrm{CH}=\mathrm{CH}_{2}, \mathrm{x}=0,1,2$, - etc.] with a increment of 14 daltons $\left(\mathrm{CH}_{2}\right)$ were observed at $\mathrm{m} / \mathrm{z} 594$, $608,622,636,650,664, \ldots, 734,748$. The ion series are of low abundance at $m / z 748$ and 788, resulting from cleavages of inner side of the allylic $C=C$ bond and the outer allylic $\mathrm{C}-\mathrm{C}$ bond, respectively. The ion series is interrupted between the two ions and terminates at $\mathrm{m} / \mathrm{z}$ 788 (Scheme 3A). These results suggest that the double bond on the 24:1-fatty acid substituent is located at C-15, counting from the carbonyl carbon of the fatty acid, and is in agreement with that reported by highenergy CAD [11]. Another series of ions which exhibit this feature is observed at $m / z 356,370,384,398, \ldots$, 496, 510, and 550. The ions between $\mathrm{m} / \mathrm{z} 510$ and 550, where the double bond is located are absent. This ion series most likely arises from further cleavage of the $\mathrm{m} / \mathrm{z}$ 650 ion (a2) via similar CRF processes (Scheme 3B). The proposed fragmentation pathways are further supported by the product ion spectrum of $d_{5}$-d18:1/ 24:1sulfatide at $m / z 893$ (Figure 1c), in which a 5-dalton mass shift was observed for the analogous ions arising 


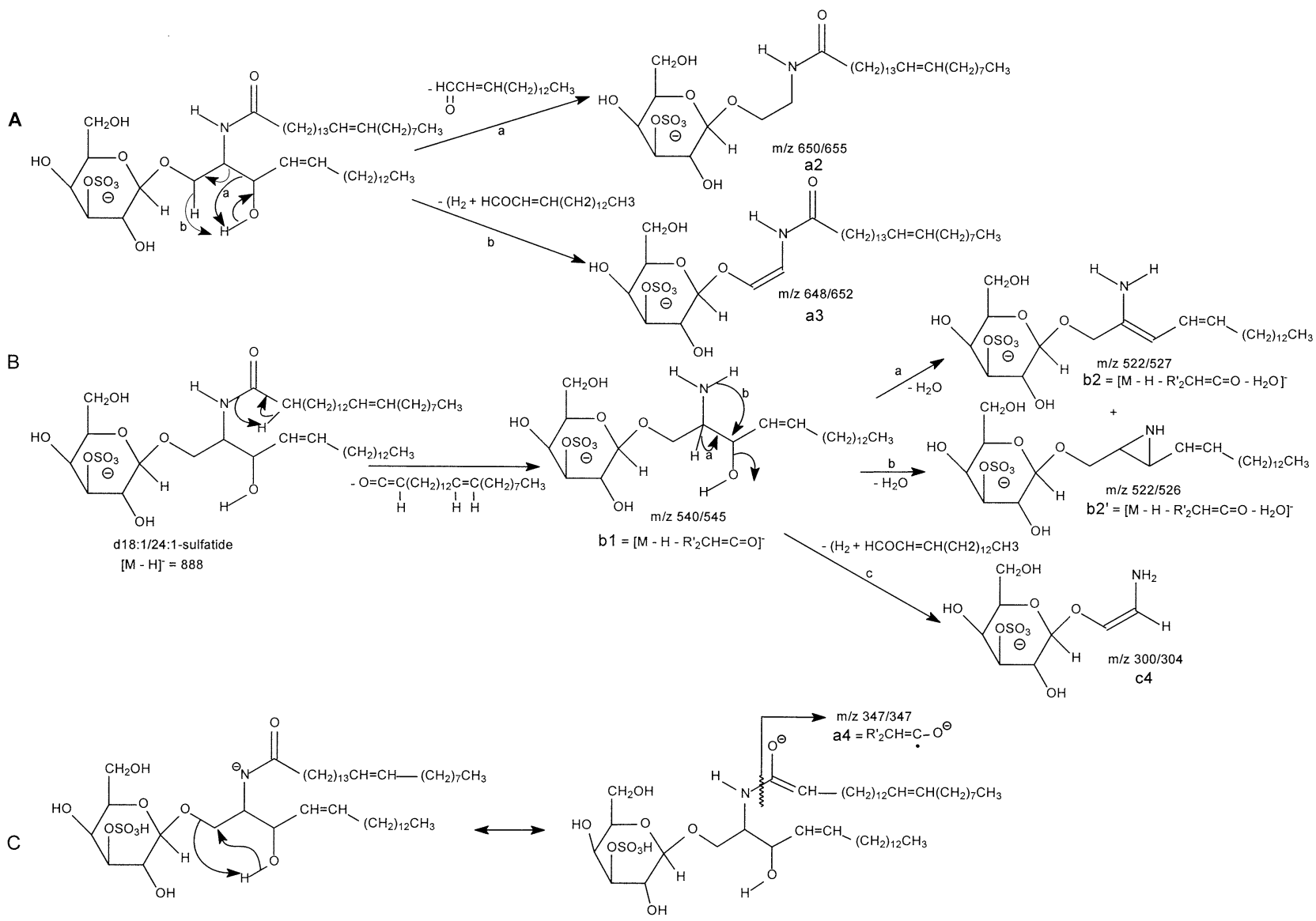

Scheme 2. The major fragmentation pathways proposed for the $\mathrm{d} 18: 1 / \mathrm{nFA}$-sulfatide subclass.

from CRF (Schemes 1, 2, 3, 4, and 5, deuterium-labeling is shown as $\mathbf{D}$, and the observed $m / z$ values are shown after /).

The apparent distinction between the ion series described above from that obtained by high-energy CAD is that the ion series in the high-energy product-ion spectrum also contains ions at $m / z 788,802,816$, etc, that are nearly equally abundant, following the absence of the ions interrupted by the unsaturated bond [11]. This may be attributable to the fact that in high-energy CAD, internal energy transfer by collision can be varied to a much smaller degree, and the average energy deposited into the ion is wide, and the energy deposition curve has a long tail to high energies. As a result, fragment ions deriving from fragmentation reactions requiring high critical energy can also be observed, and spectra with an even distribution of fragment ions can be obtained. While in the low-energy CAD process, the internal energy deposition is much narrower than in high-energy collision and fragmentation processes requiring large critical energy are thus not observed [18]. This unique pattern of the ions arising from CRF processes permits locating the position of the double bond of the fatty acid substituent. A similar pattern of the ions is also observed for d18:1/25:1-sulfatide at $\mathrm{m} / \mathrm{z}$ 902 (Figure 1d), which clearly identify the C-16 double bond of the fatty acid substituent.
The Unusual "Internal Galactose Residue Loss" Observed by Quadrupole Ion-Trap Tandem Mass Spectrometry

Another interesting finding in this study is that ions at $m / z 726$ and 708, reflecting losses of dehydrated galactose $(162 \mathrm{Da})$ and galactose $(180 \mathrm{Da})$, respectively, are also present in the $\mathrm{MS}^{2}$-spectrum of $\mathrm{m} / \mathrm{z} 888$ (Figures $1 b)$. The analogous ions from the similar losses were also observed at $m / z 742$ and 724 for d18:1/h24:1sulfatide at $m / z 904$ (Figure 3a), and appear to be more prominent. However, this internal galactose loss was not observed in the product-ion spectra of d18:1/24:1sulfatide (Figure 1a) and d18:1/h24:1-sulfatide (Figure $3 b)$ obtained with a TSQ. The galactose residue loss may arise from a rearrangement process (Scheme 4), which involves the nucleophilic attack of the charge-site at $\mathrm{C1}$ of the LCB to yield a galactose-sulfuryl-ceramide intermediate (Scheme 4, $\mathrm{d}$ ion), which undergoes a $\mathrm{C}_{6} \mathrm{H}_{10} \mathrm{O}_{5}$ or $\mathrm{C}_{6} \mathrm{H}_{12} \mathrm{O}_{6}$ loss to a 1-sulfo-ceramide (d1) or a fivemember ring anion $(\mathrm{d} 2)$, respectively. This fragmentation process is supported by the $\mathrm{MS}^{3}$-spectrum of $\mathrm{m} / \mathrm{z}$ $724(904 \rightarrow 724)$ (Figure 3c), which contains ions at $m / z$ 486 and 514, arising from losses of the LCB as an aldehyde [loss of $\mathrm{HCOCH}=\mathrm{CH}\left(\mathrm{CH}_{2}\right){ }_{12} \mathrm{CH}_{3}, 238 \mathrm{Da}$ ] and as a ketene $\left[\mathrm{CH}_{2}=\mathrm{CH}\left(\mathrm{CH}_{2}\right)_{12} \mathrm{CH}_{3}, 210 \mathrm{Da}\right]$, respectively, along with the $m / z 406$ ion, arising from cleavage of the 
A

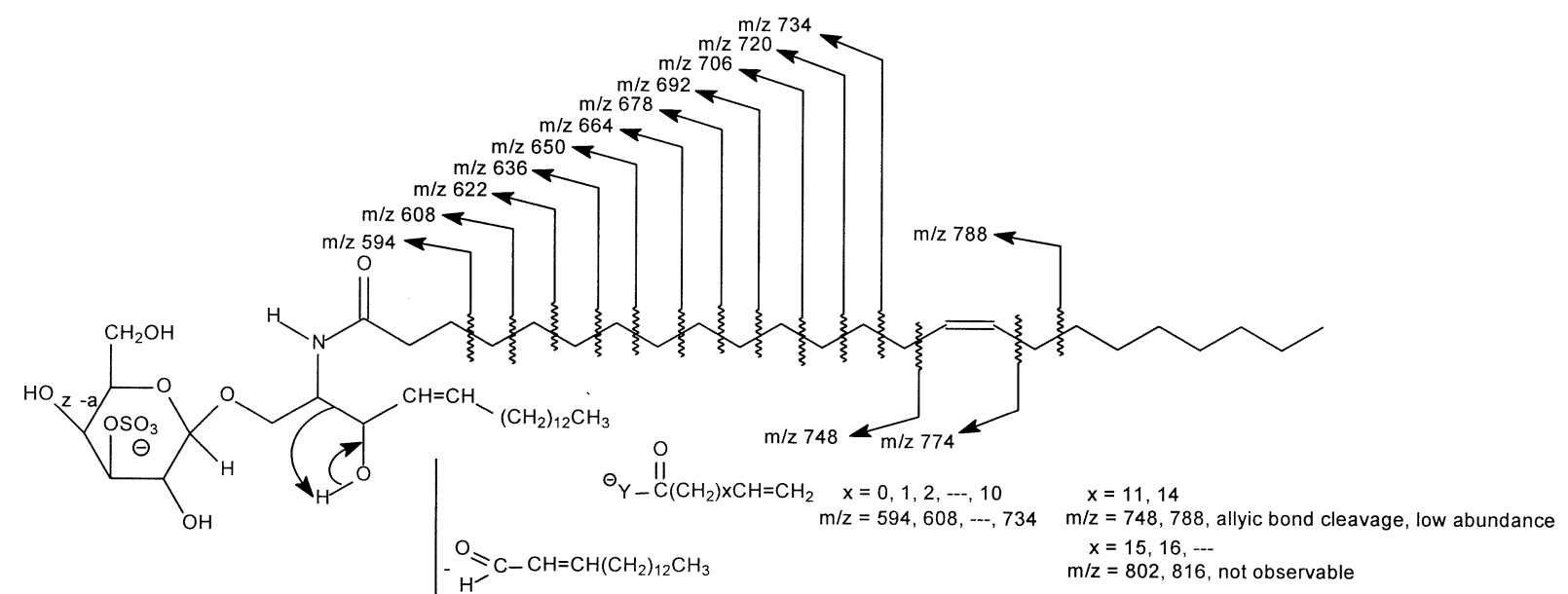

B

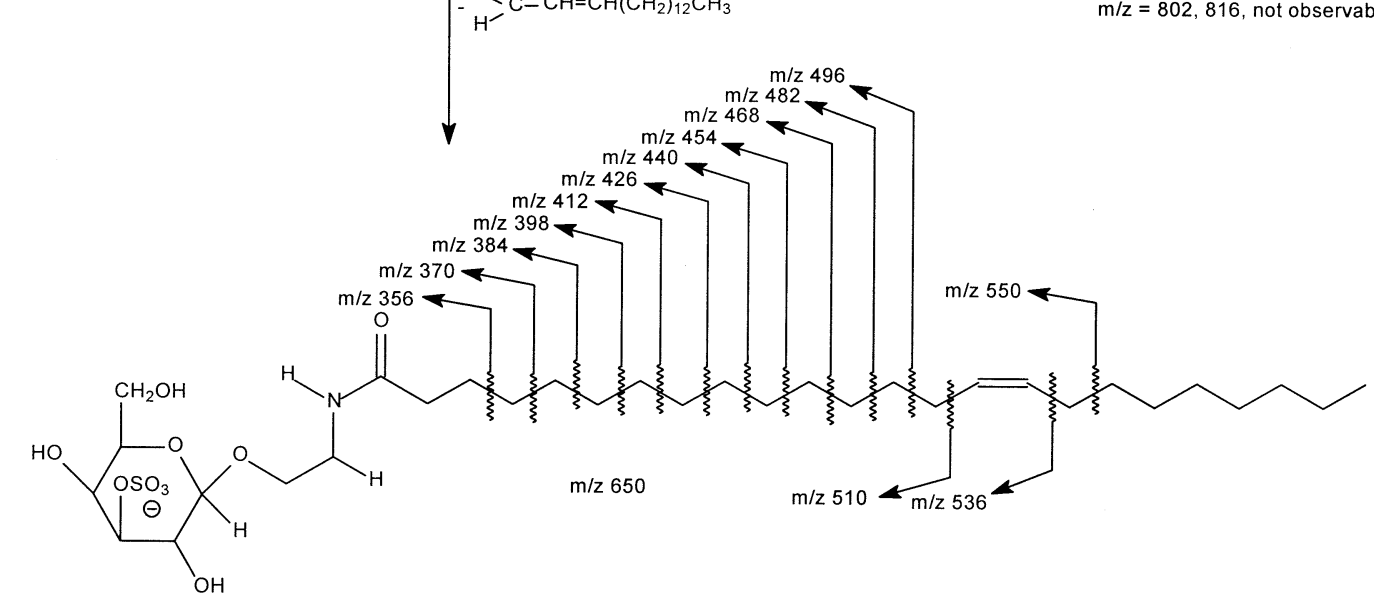

Scheme 3. The CRF pathways that yield the fragment ions informative for locating the position of unsaturation in the fatty acid substituents.

carbonyl and the $\alpha$-hydroxy carbon $\mathrm{C}-\mathrm{C}$ bond $[\mathrm{OC}-\mathrm{CH}(\mathrm{OH})]$ of the fatty acyl substituent. The results are consistent with the observation of the $m / z 470$ (888 $238)$ and 498 ions (888 - 210), arising from the analogous losses in the $\mathrm{MS}^{3}$-spectrum of $m / z 708(888 \rightarrow 708)$ (data not shown). The rearrangement pathways are further confirmed by the mass shifts observed for the corresponding ions at $m / z 728$ and 708 , in the MS $^{2}$-spectrum of the $\mathrm{d}_{5}$-d18:1/24:1-sulfatide at $m / z 893$ (Figure $1 \mathrm{c}$ ), and ions at $\mathrm{m} / \mathrm{z} 745$ and 725 in the spectrum of $\mathrm{d}_{6}-\mathrm{d} 18: 1 /$ h24:1-sulfatide at $\mathrm{m} / \mathrm{z} 910$ (Figure 3d), obtained from $\mathrm{H}-\mathrm{D}$ exchange. Loss of internal hexose residue has been previously reported for various compounds, and was mainly observed in the positive-ion mode with the protonated species under low- and high-energy CAD [20-26]. The observation of the internal galactose loss in the tandem mass spectra of the $[\mathrm{M}-\mathrm{H}]^{-}$ions of sulfatides arising from ITMS, but not from TSQ in this study is consistent with the fact that the dissociation reaction to eliminate galactose originates from a rearrangement process that requires a low activation energy. However, the configuration of the precursor ion possessing the charge that is favorable for the rearrangement process may also play a role in the ion formation $[20,21,23-25]$.
Structural Characterization of the Sulfatide with $\alpha$-Hydroxy Fatty Acyl Substituent (d18:1/hFASulfatides), and with Sphinganine LCB (d18:0/FASulfatide) Subclasses

Along with the aforementioned common ions that identify LCB, sugar, and fatty acid moieties, tandem mass spectra of sulfatides consisting of a $\alpha$-hydroxy fatty acid substituent and a d18:1-LCB (d18:1/hFA-sulfatide) contain a unique set of ions, which include prominent ions at $m / z 568,540$, and 522 , and less abundant ions at $\mathrm{m} / \mathrm{z}$ 550 and 507 . These features are demonstrated by the product-ion spectra of d18:1/h24:1-sulfatide at $\mathrm{m} / \mathrm{z} 904$ obtained with ITMS (Figure 3a), and TSQ (Figures 3b). The $m / z 540$ ion (b1) may arise from cleavage of the C-C bond between the carbonyl and the $\alpha$-hydroxy carbon $[\mathrm{OC}-\mathrm{CH}(\mathrm{OH})]$ of the fatty acid to expel a $\mathrm{CO}$, and the fatty acyl moiety as an aldehyde [loss of $(\mathrm{CO}+$ $\mathrm{HCO}\left(\mathrm{CH}_{2}\right)_{12} \mathrm{CH}=\mathrm{CH}\left(\mathrm{CH}_{2}\right)_{7} \mathrm{CH}_{3}, 364$ Da], simultaneously [19]. This is followed by elimination of a $\mathrm{H}_{2} \mathrm{O}$ to yield a $m / z 522\left(\mathbf{b} 2+\mathbf{b} 2^{\prime}\right)$ (Scheme $\left.5 \mathbf{A}\right)$. These fragmentation pathways are similar to those described earlier for the d18:1/nFA-sulfatides (Scheme 2B). The cleavage of the same $\mathrm{OC}-\mathrm{CH}(\mathrm{OH})$ bond to expel the fatty acyl moiety as an aldehyde, gives rise to the $m / z 568$ ion (b3), 


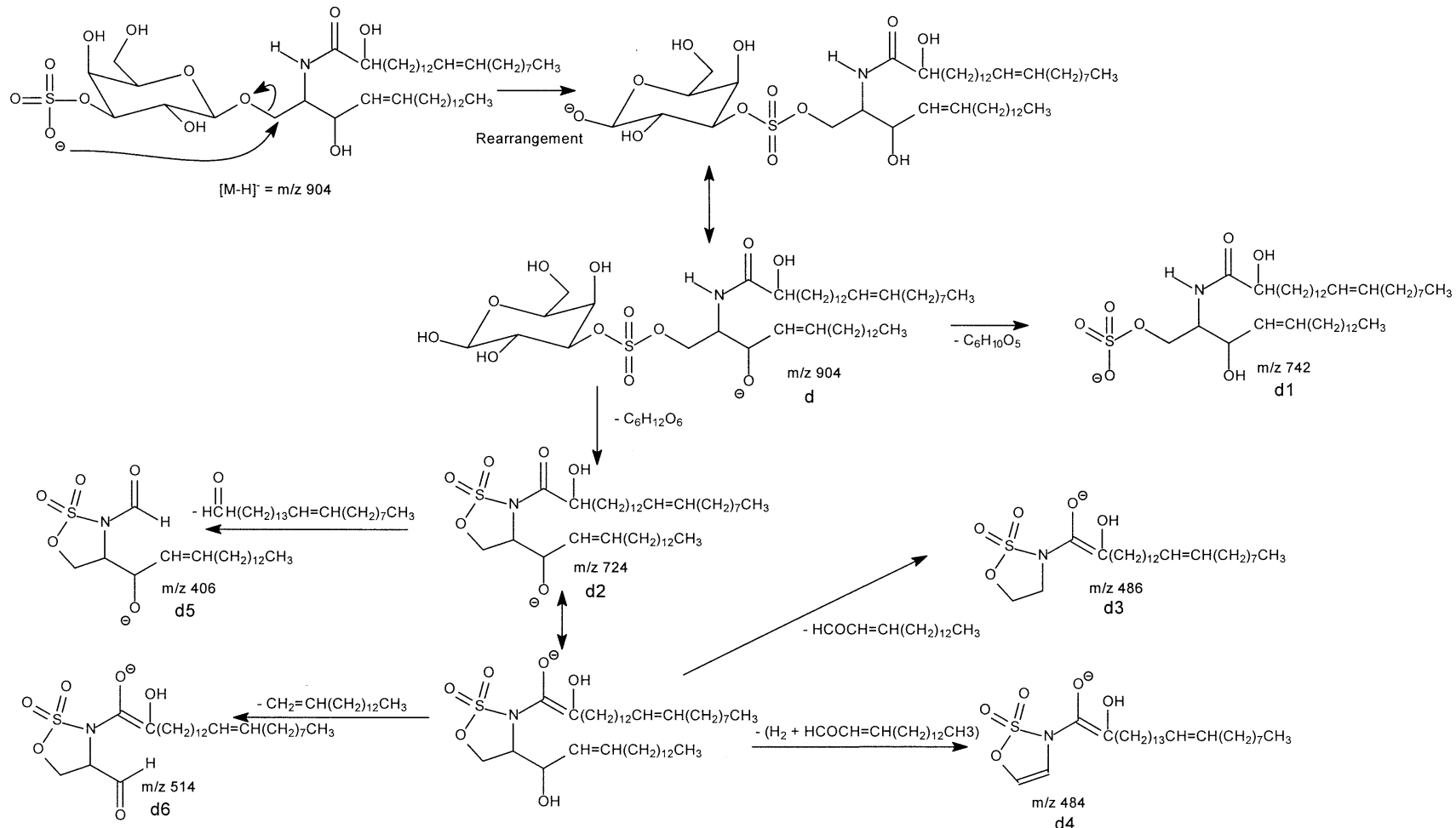

Scheme 4. The fragmentation pathways proposed for the internal galactose residue loss.
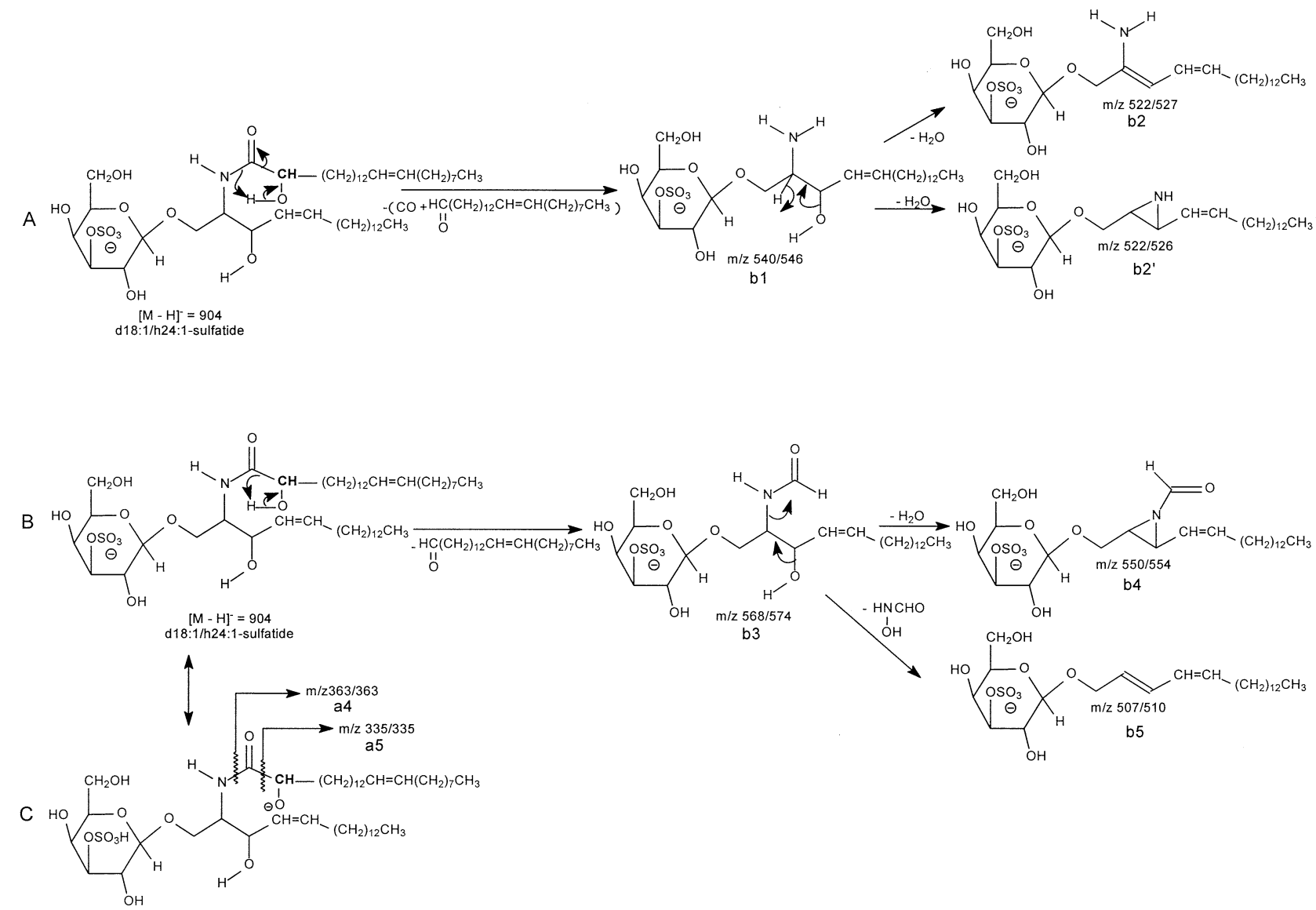

Scheme 5. The proposed fragmentation pathways specific for the LCB/hFA-sulfatide subclass. 

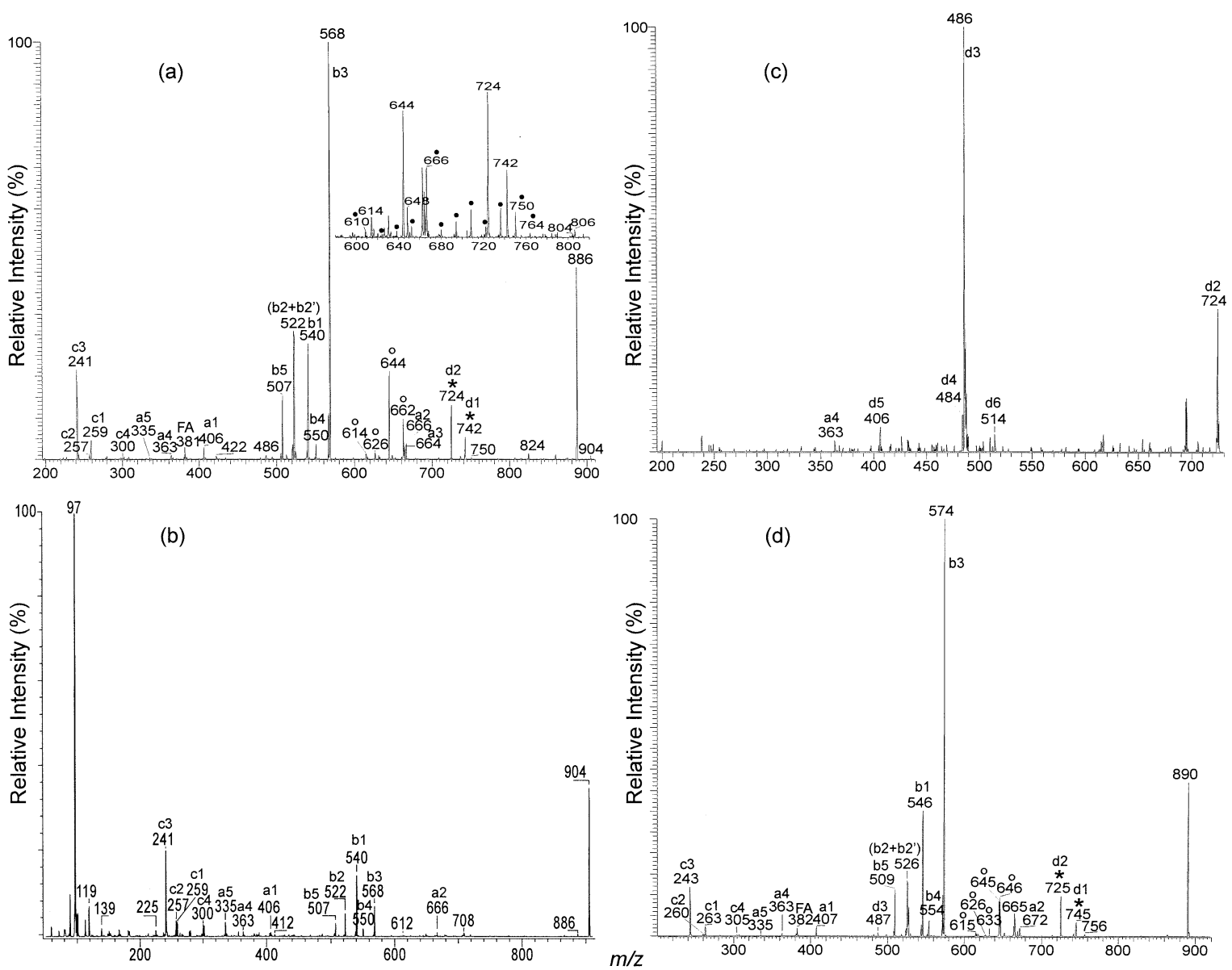

Figure 3. The $\mathrm{MS}^{2}$-spectra of the $[\mathrm{M}-\mathrm{H}]^{-}$ions of $\mathrm{d} 18: 1 / \mathrm{h} 24: 1$-sulfatide at $\mathrm{m} / \mathrm{z} 904$ obtained with (a) ITMS $(60 \%$ relative collision energy, $\mathrm{q}=0.25),(\mathbf{b})$ with TSQ $(65 \mathrm{eV})$, and $(\mathbf{d})$ of the $d_{6}-\mathrm{d} 18: 1 / \mathrm{h} 24: 1-$ sulfatide at $\mathrm{m} / \mathrm{z} 910$ obtained with ITMS (60\% relative collision energy, $\mathrm{q}=0.25)$. Panel (c) is the MS $^{3}$-spectrum of $m / z 724(904 \rightarrow 724)$. The spectrum shown in inset, Panel a (acquired under the same condition, but with $\mathrm{q}=0.45$ ) is featured by the ion series at $\mathrm{m} / \mathrm{z} 764,750,736$, , 610 (marked with a center dot) arising from CRF, indicating that the double bond of the fatty acyl substituent is located at C-15. Ions arising from the internal galactose residue losses are marked with an asterisk; ions reflecting the ceramide moiety are marked with a degree symbol.

which yields the $m / z 550$ (568 - 18) (b4) ion by loss of $\mathrm{H}_{2} \mathrm{O}$ (Scheme 5B). Further dissociation of $m / z 568$ also gives rise to $\mathrm{m} / \mathrm{z} 507$ (b5), as evidenced by the $\mathrm{MS}^{3}$ spectrum of $m / z 568$ (data not shown). The $m / z 507$ ion is not present in the product-ion spectrum of d18:1/ nFA-sulfatide, in which precursor ion (b3 type) leading to such loss is not available. The homolytic cleavage of the same bond also yields the $\mathrm{m} / \mathrm{z} 335$ ion (a5). The presence of this ion together with the $\mathrm{m} / \mathrm{z} 363$ ion (a4), resulting from homolytic cleavage of the $\mathrm{NH}-\mathrm{CO}$ bond (Scheme 5C), indicates that the anionic charge site most likely resides on the $\alpha$-hydroxyl of the fatty acid substituent. These observations further support the earlier notion that fragmentation pathways for sulfatides under low energy CAD involve more than one charge site. The proposed fragmentation pathways (Scheme 5) are consistent with the mass shifts of the analogous ions observed for $d_{6}$-d18:1/h24:1-sulfatide (Figure 3d), and are confirmed by the $\mathrm{MS}^{2}$-spectrum of the $\mathrm{m} / \mathrm{z} 908$ ion that arises from d18:0/h24:0-sulfatide (Figure 4a), prepared by hydrogenation of $\mathrm{d} 18: 1 / \mathrm{h} 24: 1$-sulfatide. The spectrum contains the analogous ions at $m / z 570$ (b3), 552 (b4), 542 (b1), 524 (b2+b2'), and 509 (b5), which show a mass shift of 2, reflecting the d18:0-LCB.

The ion series deriving from classical CRF are also observed in the $\mathrm{MS}^{2}$-spectra of sulfatides containing an $\alpha$-hydroxyl fatty acid substituent (LCB/hFA-sulfatide) obtained with an ITMS, and provide information to identify the position of double bond of the fatty acyl substituent. As shown in Figure $3 \mathrm{a}$, the $\mathrm{MS}^{2}$-spectrum of the d18:1/h24:1-sulfatide (inset) gives the ion clusters at $m / z 610,624,638,652,666,680,694,708,722,736,750$, and 764 , with the last $(\mathrm{m} / \mathrm{z} 764)$ is the least abundant. This information clearly demonstrates that the double bond of the fatty acyl substituent resides at C-15, although the ion series are of low-abundance. In contrast, the ion series are not present in the product-ion spectrum of d18:1/h24:1-sulfatide obtained with a TSQ 
(a) Full ms ${ }^{2} 908.7$ (d18:0/h24:0-sulfatide) @60

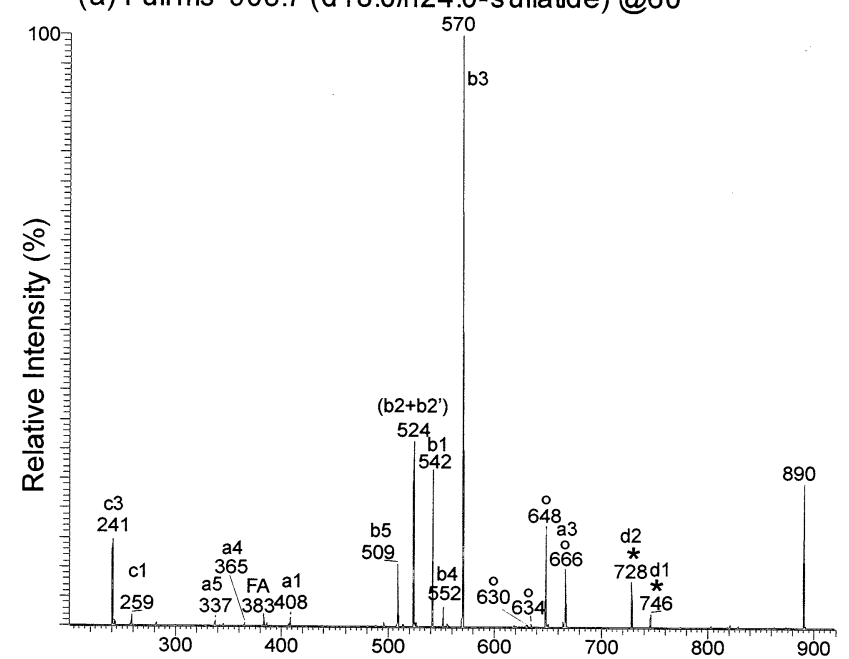

(b) Full ms ${ }^{2} 892.8$ (d18:0/24:0-sulfatide) @60

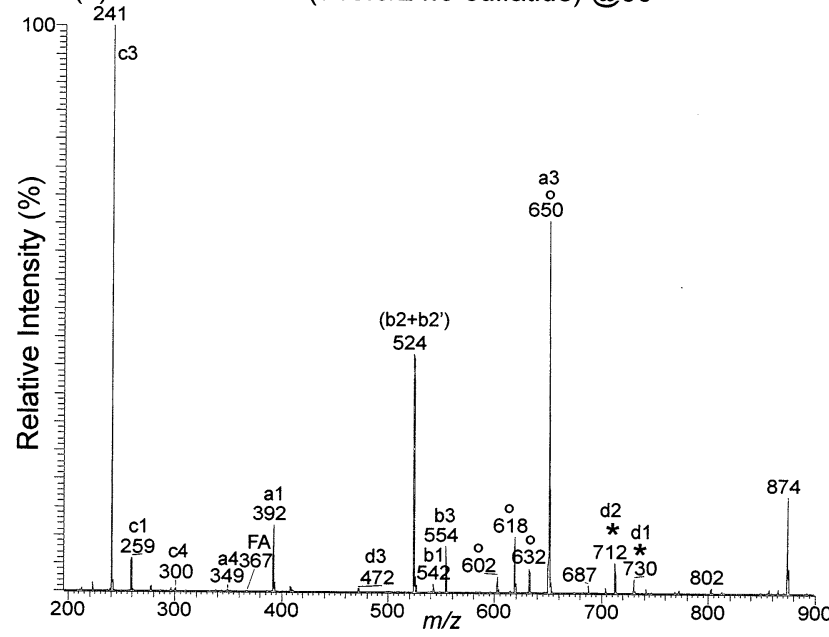

Figure 4. The $\mathrm{MS}^{2}$-spectra of the $[\mathrm{M}-\mathrm{H}]^{-}$ions of (a) d18:0/ h24:0-sulfatide at $\mathrm{m} / \mathrm{z} 908$ and (b) of d18:0/24:0-sulfatide at $\mathrm{m} / \mathrm{z}$ 892. Ions arising from the internal galactose residue losses are marked with an asterisk; ions reflecting the ceramide moiety are marked with a degree symbol.

(Figure $3 b$ ). The results may indicate that compound type (d18:1/nFA-sulfatide versus d18:1/hFA-sulfatide), mass of collision target (He versus Ar), and target gas pressure (0.7 mTorr versus $2.3 \mathrm{mTorr}$ ) used in the CAD processes (ITMS versus TSQ) may be more crucial than energy requirement for CRF to occur [17]. Collision activation in TSQ is a multiple collision process that results in consecutive fragmentation processes, while resonance excitation is the major process for ITMS. The $\mathrm{OC}-\mathrm{CH}(\mathrm{OH})$ bond of the fatty acyl substituent may be too labile and preferentially cleaved by the multiple collision processes, and thus CRF processes that require a stable charge site on the precursor, become less competitive [15]. This is also consistent with the observation of the internal galactose loss (via rearrangement) in the $\mathrm{MS}^{2}$-spectra obtained with an ITMS but not those acquired by TSQ.

As described earlier, the expulsion of an anhydro galactosylpyranose 3-sulfate (242 Da) resulted in a deprotonated ceramide anion, which undergoes consecutive dissociation to the ion series that identify the ceramide moiety. The ion series for d18:0/24:0-sulfatide (Figure $4 b$ ) were observed at $m / z 650$ ion, equivalent to a deprotonated d18:0/24:0-ceramide ion, together with ions at $m / z 632\left(650-\mathrm{H}_{2} \mathrm{O}\right), 618\left[650-\left(\mathrm{H}_{2}+\mathrm{HCHO}\right)\right]$, and $602\left[650-\left(\mathrm{H}_{2} \mathrm{O}+\mathrm{HCHO}\right)\right]$. However, the ion at $m / z 620(650-\mathrm{HCHO})$, reflecting loss of a $\mathrm{HCHO}$ is not present. Similar results were also observed for the d18:0/h24:0-sulfatide at $\mathrm{m} / \mathrm{z} 908$ (Figure 4a). The information indicates that the molecule consists of a sphinganine, rather than a sphingosine LCB, consistent with the findings previously reported for the ceramides possessing a sphinganine LCB [19]. This feature in the ion series provides a simple method to distinguish a d18:0/FA-sulfatide from a d18:1/FA-sulfatide subclass. The structural information including the sugar moiety, fatty acyl substituent and LCB as described above permits unequivocal characterization of the sulfatide subclass with a sphinganine LCB (d18:0/FA-sulfatide).

\section{Conclusions}

The superb sensitivity of ESI in combination with tandem mass spectrometry provides information for comprehensive structural characterization of sulfatides. Tandem mass spectra of sulfatide with n-FA substutients are substantially distinguishable from its hFAsulfatide counterparts, with the latters are featured by the prominent ions of $b 1, b 2, b 3, b 4$, and b5 ions. Classical CRF processes that yield the ion series leading to assignment of the position of double bond in the fatty acid substituents that were previously reported only by a tandem sector mass spectrometer are also present. However, this ion series are of low abundance, and complete structural identification including assignment of the position of double bond of the fatty acyl, thus, requires sustained signal-averaging and sub-nanomole amounts of sample. $\mathrm{MS}^{2}$-spectra from ITMS provide a more comprehensive structural information regarding the identity of the ceramide moiety. The observation of an internal galactose loss for the $[\mathrm{M}-\mathrm{H}]^{-}$ion of sulfatides by ITMS in the negative-ion mode is also unique. Nevertheless, spectra from ITMS are restricted by the low-mass cutoff and thus, low-mass fragment ions such as $m / z 97$, a diagnostic ion for sulfate class, is lost. More improvements in sensitivity and in low-mass coverage are required for complete structural characterization. Therefore, the implementation of analyses with new linear ion-trap/triple quadrupole instrument may have a niche in the structural determination of sulfatides in future.

\section{Acknowledgments}

This research was supported by U.S. Public Health Service grants P41-RR-00954，R37-DK-34388，P60-DK-20579, P30-DK56341, and 
P01-HL-57-278 and a grant (996003) from the Juvenile Diabetes Foundation.

\section{References}

1. Gurr, M. I.; James, A. T. Lipid Biochemistry; Cornell University Press: Ithaca, NY, 1971; pp 149-173.

2. Buschard, K.; Josefsen, K.; Hansen, S. V.; Horn, T.; Marshall, M. O.; Persson, H.; Mansson, J. E.; Fredman, P. Sulphatide in Islets of Langerhans and in Organs Affected in Diabetic Late Complications: A Study in Human and Animal Tissue. Diabetologia 1994, 10, 1000-1006.

3. Fredman, P.; Mansson, J. E.; Rynmark, B. M.; Josefsen, K.; Ekblond, A.; Halldner, L.; Osterbye, T.; Horn, T.; Buschard, K. The Glycosphingolipid Sulfatide in the Islets of Langerhans in Rat Pancreas is Processed Through Recycling: Possible Involvement in Insulin Trafficking. Glycobiology 2000, 10, 39-50.

4. Marinier, A.; Martel, A.; Banville, J.; Bachand, C.; Remillard, R.; Lapointe, P.; Turmel, B.; Menard, M.; Harte, W. E., Jr.; Wright, J. J.; Todderud, G.; Tramposch, K. M.; Bajorath, J.; Hollenbaugh, D.; Aruffo, A. J. Sulfated Galactocerebrosides as Potential Antiinflammatory Agents. Med. Chem. 1997, 40, 3234-3247.

5. Higashi, H.; Suzuki, Y.; Mukaida, N.; Takahashi, N.; Miyamoto, D.; Matsushima, K. Intervention in Endotoxin Shock by Sulfatide (I3SO3-GalCer) with Concomitant Reduction in Tumor Necrosis Factor $\alpha$ Production. Infect. Immun. 1997, 65, 1223-1227.

6. Konno, A.; Nunogami, K.; Wada, T.; Yachie, A.; Suzuki, Y.; Takahashi, N.; Suzuki, T.; Miyamoto, D.; Kiso, M.; Hasegawa, A.; Miyawaki, T. Inhibitory Action of Sulfatide, a Putative Ligand for L-Selectin, on B Cell Proliferation and Ig Production. Int. Immunol. 1996, 8, 1905-1913.

7. Suzuki, T.; Sometani, A.; Yamazaki, Y.; Horiike, G.; Mizutani, Y.; Masuda, H.; Yamada, M.; Tahara, H.; Xu, G.; Miyamoto, D.; Oku, N.; Okada, S.; Kiso, M.; Hasegawa, A.; Ito, T.; Kawaoka, Y.; Suzuki, Y. Sulphatide Binds to Human and Animal Influenza A Viruses, and Inhibits the Viral Infection. Biochem. J. 1996, 318(Pt 2), 389-393.

8. Ankel, H.; Capobianchi, M. R.; Frezza, F.; Castilletti, C.; Dianzani, F. Interferon Induction by HIV-1-Infected Cells: A Possible Role of Sulfatides or Related Glycolipids. Virology 1996, 221, 113-119.

9. Squadrito, F.; Altavilla, D.; Squadrito, G.; Campo, G. M.; Arlotta, M.; Quartarone, C.; Minutoli, L.; Ferlito, M.; Saitta, A.; Caputi, A. P. Sulfatide Reduces Leucocyte Accumulation and Reverts Vascular Failure in Splanchnic Artery Occlusion Shock. Eur. J. Pharmacol. 1998, 361, 101-108.

10. Fantini, J.; Hammache, D.; Delezay, O.; Pieroni, G.; Tamalet, C.; Yahi, N. Sulfatide Inhibits HIV-1 Entry into CD4-/ CXCR4+ Cells. Virology 1998, 246, 211-220.

11. Ohashi, Y.; Nagai, Y. Fast-Atom-Bombardment Chemistry of Sulfatide (3-Sulfogalactosylceramide). Carbohydr. Res. 1991, 221, 235-243.

12. Hsu, F. F.; Bohrer, A.; Turk, J. Electrospray Ionization Tandem Mass Spectrometric Analysis of Sulfatide. Determination of Fragmentation Patterns and Characterization of Molecular Species Expressed in Brain and in Pancreatic Islets. Biochim. Biophys. Acta 1998, 1392, 202-216.
13. Hsu, F. F., Turk, J. Tandem Quadrupole Mass Spectrometry of Sphingomyelin and Sulfatides. In The Encyclopedia of Mass Spectrometry. Applications in Biochemistry, Biology and Medicine. Part A; Caprioli, R.; Gross, M. L., Eds.), Elsevier Science: New York, in press.

14. Louris, J. N.; Cooks, R. G.; Syka, J. E. P.; Kelley, P. E.; Stafford, G. C., Jr.; Todd, J. F. J. Instrumentation, Applications, and Energy Deposition in Quadrupole Ion-Trap Tandem Mass Spectrometry. Anal. Chem. 1997, 59, 1677-1685.

15. Gross, M. L. Charge Remote Fragmentations: Methods, Mechanism, and Applications. Int. Mass Spectrom. Ion Processes 1992, 118/119, 137-158.

16. Cheng, C.; Gross, M. L. Application and Mechanisms of Charge-Remote Fragmentation. Mass Spectrom. Rev. 2000, 19, 398-420.

17. Wysocki, V. H.; Ross, M. M. Charge-Remote Fragmentation of Gas-Phase Ions: Mechanistic and Energetic Considerations in the Dissociation of Long-Chain Functionalized Alkanes and Alkenes. Int. J. Mass Spectrom. Ion Processes 1991, 104, 179-211.

18. Vekey, K. Internal Energy Effects in Mass Spectrometry. J. Mass Spectrom. 1996, 31, 445-463.

19. Hsu, F. F.; Turk, J. Characterization of Ceramides by Low Energy Collisional-Activated Dissociation Tandem Mass Spectrometry with Negative-Ion Electrospray Ionization. J. Am. Soc. Mass Spectrom. 2002, 13, 558-570.

20. Brull, L. P.; Heerma, W.; Thomas-Oates, J.; Haverkamp, J.; Kovacik, V.; Kovac, P. Loss of internal $1 \rightarrow 6$ Substituted Monosaccharide Residues from Underivatized and Per-OMethylated Trisaccharides. J. Am. Soc. Mass Spectrom. 1997, 8, 43-49.

21. Brull, L. P.; Kovacik, V.; Thomas-Oates, J.; Heerma, W.; Haverkamp, J. Sodium-Cationized Oligosaccharides Do Not Appear to Undergo "Internal Residue Loss" Rearrangement Processes on Tandem Mass Spectrometry. Rapid Commun. Mass Spectrom. 1998, 12, 1520-1532.

22. Warrack, B. M.; Hail, M. E.; Triolo, A.; Animati, F.; Seraglia, R.; Traldi, P. Observation of Internal Monosaccharide Losses in the Collisionally Activated Dissociation Mass Spectra of Anthracycline Aminodisaccharides. J. Am. Soc. Mass Spectrom. 1998, 9, 710-715.

23. Ma, Y. L.; Vedernikova, I.; Van den Heuvel, H.; Claeys, M. Internal Glucose Residue Loss in Pprotonated O-Diglycosyl Flavonoids Upon Low-Energy Collision-Induced Dissociation. J. Am. Soc. Mass Spectrom. 2000, 11, 136-144.

24. Harvey, D. J.; Mattu, T. S.; Wormald, M. R.; Royle, L.; Dwek, R. A.; Rudd, P. M. "Internal Residue Loss" Rearrangement During the Fragmentation of Carbohydrates Derivatized at the Reducing Terminus. Anal. Chem. 2002, 74, 734-740.

25. Tadano-Aritomi, K.; Hikita, T.; Kubota, M.; Kasama, T.; Toma, K.; Hakomori, S.; Ishizuka, I. Internal Residue Loss Produced by Rearrangement of a Novel Cationic Glycosphingolipid, Glyceroplasmalopsycholine, in Collision-Induced Dissociation. J. Mass Spectrom. 2003, 38, 715-722.

26. Hsu, F. F.; Turk, J. Characterization of Phosphatidylinositol, Phosphatidylinositol-4-Phosphate, and Phosphatidylinositol4,5-Bisphosphate by Electrospray Ionization Tandem Mass Spectrometry: A Mechanistic Study. J. Am. Soc. Mass Spectrom. 2000, 11, 986-999. 